\title{
Development on Teaching Material Management System based on SSi Framework
}

\author{
Zhe $\mathrm{Li}^{1, \mathrm{a}}$, Hui Ma ${ }^{2, \mathrm{~b}}$ \\ ${ }^{1}$ College of International Exchange, Bohai University, Jinzhou, 121013, China \\ ${ }^{2}$ School of Mathematics and Physics, Bohai University, Jinzhou, 121013, China \\ a503412508@qq.com, bhuima2016@163.com
} Keywords: SSi framework; teaching material management system; function design; business layer
implementation; Struts; Spring; iBatis

\begin{abstract}
Constructing scientific and practical teaching material management system, managers can use the network to deal with related work, students and teachers can always check the progress of teaching material period of related work, check the cost of teaching material, contribute to the management of transparency, improve work efficiency, and improve educational administration level. The system based on the SSi framework to achieve the full management of teaching material, including planning management, order management, inventory management, distribution management, system maintenance and basic information management. The result of the research solve the key technical problems of software development, such as reducing the code coupling, enhancing the reusability and robustness of the system, speeding up the system development efficiency and reducing the later maintenance.
\end{abstract}

\section{Introduction}

Teaching material is the media for teachers and students to carry out teaching activities, is the specific embodiment of outline teaching objectives. Textbooks through the refinement of the outline teaching objectives, and through the selection and practice activities designed to make the teaching objectives clear and specific. Continued years enrollment of higher education, the number of students in school increased rapidly, the demand for teaching material also increased significantly. With the deepening of higher education teaching reform, the used kinds of teaching material is also more and more. Traditional manual management and less efficient application software systems, the increasing labor intensity of the staff, the time it takes to obtain effective information is getting longer and longer. Facing the new changes in the construction of teaching material, the teaching management department of colleges and universities should strengthen the reform of teaching material management in order to meet the needs of modern education teaching reform while strengthening the service consciousness and improving the service quality. The construction of scientific and practical teaching material management system, improve the educational administration management system in the teaching management part, the management personnel can use the network to deal with the relevant work, students and teachers can check the progress of teaching material at any time, check the teaching material expense information, management work transparency, improve work efficiency, improve the level of educational management.

MVC is the most popular software development framework, the system is divided into three parts, including model, view and controller. Model, a transaction logic module, contains business data and deal with the business rules, which is the core of MVC layer; view, established and based on the data model, the user interaction with the system interface, only responsible for receiving users' data, provide a variety of data validation function, display the results of the system processing, without dealing with any actual business. Controller, a data flow control module, does not deal with any business logic, but the coordination of the view layer and the model layer during the work, also to deal with the control data processing, control the flow of data. MVC parts are independent of each other, with low coupling, high reuse, easy to maintain, easy to expand and so on, developers can focus on business logic, is conducive to software engineering management and improve 
development efficiency. J2EE domain contains a variety of MVC framework technology, Struts2, $\mathrm{SSH}$ and SSi is the mainstream application framework, and the system based on SSi framework development.

\section{SSi Framework Structure}

$\mathrm{SSi}$, consists of Struts, Spring and Ibatis, the combination of three technical framework of the three-tier technology architecture, from top to bottom is the presentation layer, business logic layer, data persistence layer, mutual interaction, integration and implementation of Web-side functions. The frame structure is shown in Fig.1.

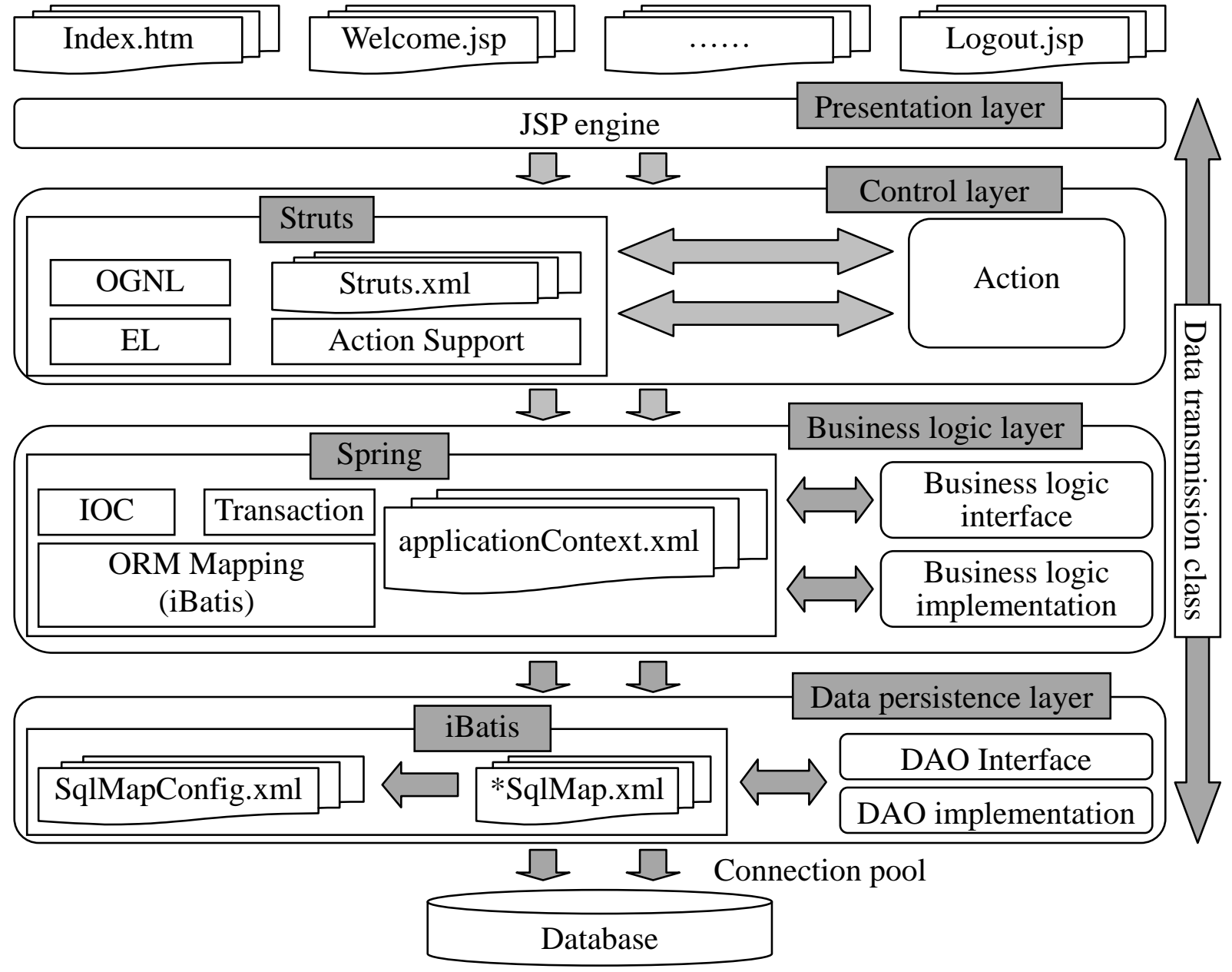

Fig. 1. SSi Framework structure

(1) Struts framework using Struts2, the core component is the Action category, used to encapsulate the client's request and call the business layer from the Service category, through the web.xml file configuration filter, through the struts.xml file configuration client page request. Web request in the process of Struts2 framework is: the client after the initialization point to the Servlet request; request through the filter call, ask to decide whether to call any Action; If you need to call ActionProxy through Configuration Manager to find the framework of the configuration file information, find the need to call the Action category, and then create an example of ActionInvocation; finally call Action, after the implementation of struts.xml, find the corresponding results then return.

(2) Spring framework, a lightweight framework, which is based on AOP and IOC's multi-tier architecture. AOP technology is mainly used to separate business logic and system services, improve cohesion; IOC technology used to relieve the program between the excessive coupling and simplify the development. Spring framework is responsible for organizing the work of various business logic, including the business logic and data access objects, services and transaction 
management through the configuration file organized. Spring's core is to support reusable business and data access objects, based on the idea of delay injection of the assembly code to improve the system scalability and flexibility to achieve the plug-in programming; AOP thought to reduce the code repetition rate, to promote the efficiency of solutions.

(3) IBatis is a semi-automated data persistence layer framework, including SQLMaps and DAO two types, by the SQL Maps components to complete the Java object on the relational database CRUD operation, through the DAO component access the database. Compared with Hibernate and JPA, iBatis is characterized by semi-automatic. In terms of Hibernate, which has completely encapsulated the structure of the database, from a set of POJO to the database table mapping mechanism; in the development process, only need to define its mapping, you can achieve database access, or even do not need to master the SQL syntax. IBatis is a good solution to this problem, allowing the program developer to customize the value of the SQL configuration bean, and also allow the database to extend the standard SQL syntax.

\section{Function Design}

Functional frame structure is the result of simulation, is decomposition of system function, graphics according to the function of the affiliation, the graph of each rectangular frame are called a functional module. The subsystems of the management information system can be seen as the function of the lower target of the system, and each function can continue to be decomposed into more functions. Functional decomposition process from large to small, from thick to thin, from top to bottom. Conceptually, the upper layer function control the lower layer function, the more the upper layer function, the more general, the more the underlying function, the more specific. The process of functional decomposition is a process from abstract to concrete, from complex to simple. Function modules can be divided according to the specific circumstances larger or smaller, the smallest decomposition of the functional modules can be a process of each process, and the larger function module can be a task to complete a set of procedures. The function design of the system is shown in Fig .2.

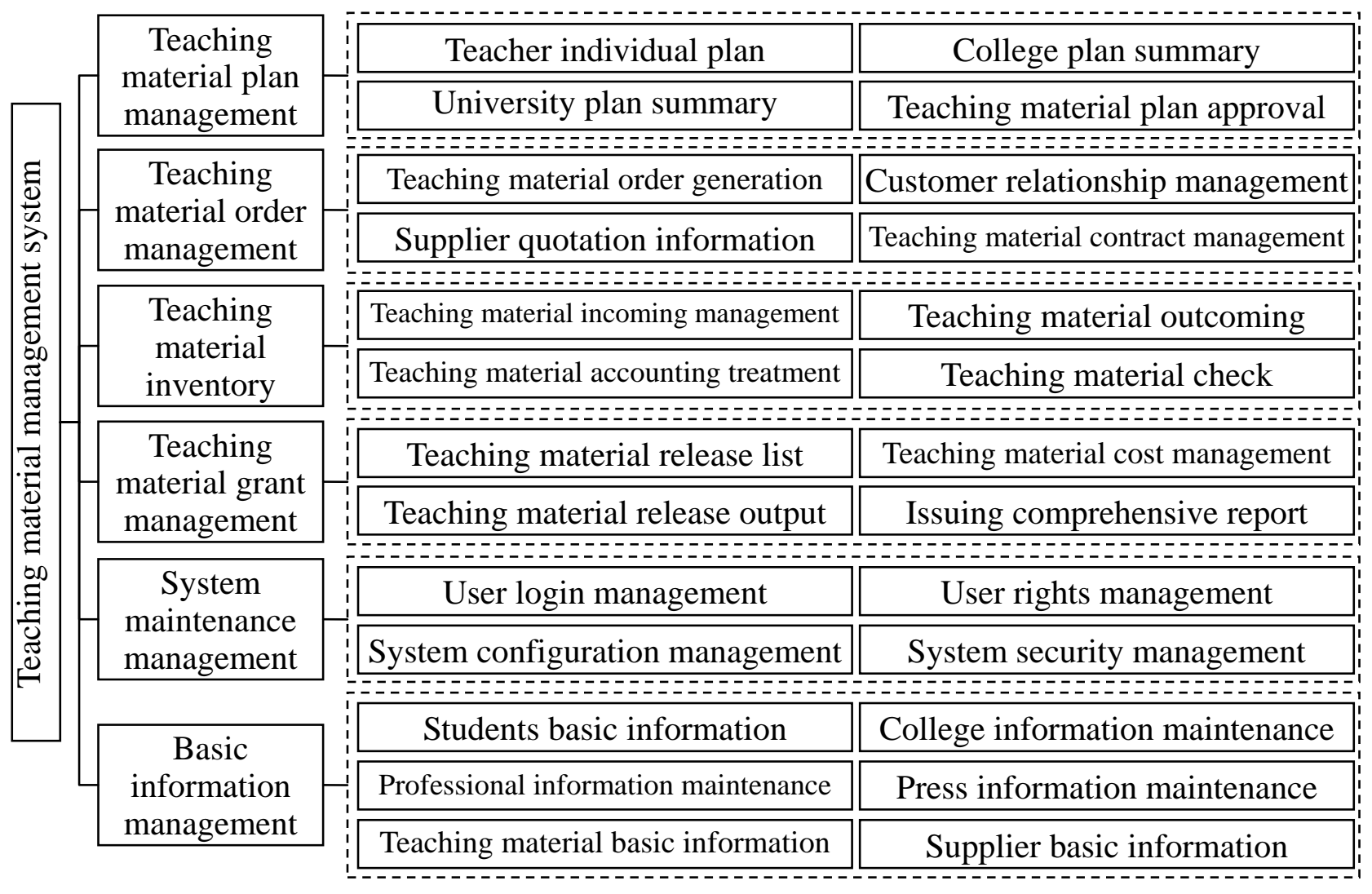

Fig. 2. Function on teaching material management system 
(1) Teaching material management system. Do a good job in teaching material management, meet the supply of teaching material, which has an important role for the implementation of teaching plans, stable teaching order, improve teaching quality, deepen the teaching reform and so on. In order to make the teaching material plan subject to the teaching plan, we must base on the characteristics of teaching material and research program management process.

(2) Teaching material order management. According to the summary of teaching material plan and the inventory of the teaching material, it is determined that the number of material used in this semester will be deducted from the inventory, and the basic information of teaching material will be processed and the order will be formed as the original certificate of the teaching material.

(3) Teaching material inventory management. Including entering-warehouse management, out-of-warehouse management and inventory processing and so on. After the purchase of teaching material in the warehouse, before the use of teaching material. Regularly check and the statistics on inventory, and make the incomplete, damaged or lost one in a timely solution. Teaching material management center timely update the inventory processing and warehouse registration.

(4) Teaching material grant management. When the ordered teaching materials arrived, the teaching material center inform the college students to receive according to the teaching plan. According to the list of teaching material from class or individual students, deal with students' personal teaching material expense account, while the teaching material will be collected for inventory processing. Print out the out-of-warehouse list details, and distribute the teaching material to the class or individual.

(5) System maintenance management. The task of system maintenance is to correct the hidden errors found in the process of using the software system, and expand the new function and performance requirements put forward by the user during the operation. The purpose is to maintain the normal operation of the software system. Configuration management is an important work of system maintenance, the goal is to record the evolution of software products, ensure that software developers at all stages in the software life cycle can get accurate product configuration.

(6) Basic information management. Using unified interface to maintain the basic information on the system, which is easy to centralized the management of information, reduce maintenance costs, enhance the normative data. Correspondence saving code with name in basic information table, the business table only save the code data, do not save the name data, reduce data redundancy, and reduce maintenance workload.

\section{Business Layer Implementation}

Business layer is located between the control layer and the persistence layer, is used to deal with the business logic and have a connecting link between the preceding and the following. Business logic is managed by the Spring framework, which implements the business interface and completes the operation with the persistence layer by calling the DAO Interface. Business layer structure is shown in Fig .3.

(1) Define business logic component interface. Interfaces are a set of declarations that improve the flexibility and scalability of software system. Nutrition ratio standard management includes four users' requests, namely, add, modify, delete and query. Business logic component need to define these four methods, the system controller components program for the four interfaces, you can achieve the implementation class separation of the controller components and business logic components.

(2) Business logic component implementation category. Implementation category is to achieve those methods of the interface in method body, business logic component interface must pass through the implementation category to achieve specific business functions. In order to let the business logic component accept the Spring container inject to the DAO component, it is necessary to provide the corresponding setter method for the business logic component. Business logic category implements the operation of the database through the data persistence layer. Therefore, the business logic method needs to capture the abnormal data persistence layer and throw the abnormal user custom, so as to provide the operator with richer information. 
(3) Configure business logic component. Including three configurations, first is to deploy the business logic component implementation category in Spring container, and increase control for business logic method; second is to configure the business logic components rely on the DAO components; third, increase the transaction control for the business logic components, for BeanNameAutoProxyCreator post processor, Spring introduce the incoming transaction interceptor, let target bean generate to transaction proxy, so firstly define the BeanNameAutoProxyCreator post processor, and then configure the transaction manager bean and configure the transaction interceptor bean.

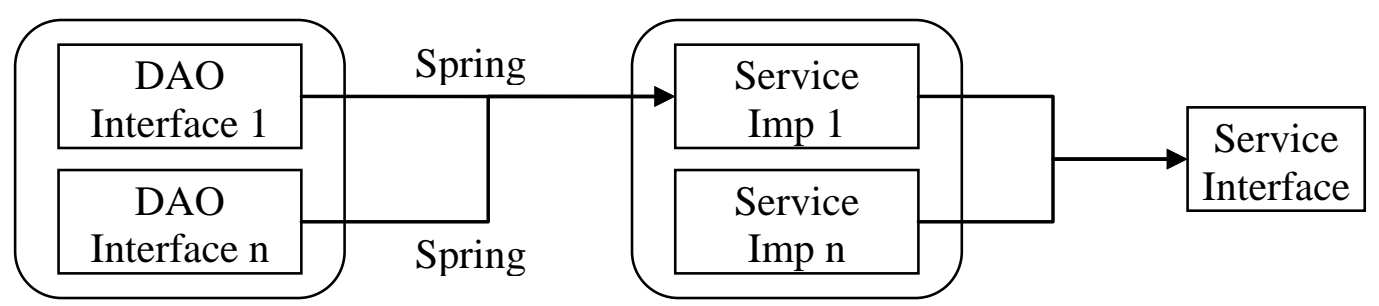

Fig. 3. Business layer structure

\section{Conclusion}

Teaching material management is the work of educational management, teaching material management work is the basic guarantee of teaching work to carry out and is also the inherent requirement of teachers and students' meet to use teaching materials. The most important function of teaching material is to present the knowledge of subject systematically. Therefore, the teaching material has the characteristics of authority and indicative. Efficient teaching material is an important guarantee to deepen the teaching reform, promote quality education, cultivate innovative talents, not only the focus of teaching quality but also the results of teaching reform concentrated reflection. With the rapid development of science and technology, resulting in a large number of teaching materials with reformed features, new levels, new content and new system. Developing teaching material management system is an important part of university informational construction. The system is based on SSi framework design, reduce code coupling, enhance system reusability and robustness, speed up system development efficiency, reduce post-maintenance, all-roundly improve system performance and quality.

\section{References}

[1] M. N. Liu, "Design and implementation of teaching material management system based on JAVA Web," Digital Technology and Application, vol. 34, no. 1, pp. 173-174, 2016.

[2] J. Qiu, G. Y. Peng, T. W. Pu, et al., "Design and implementation of university teaching material management system based on B/S architecture," Fujian Computer, vol. 31, no. 5, pp. 110-111, 2015.

[3] G. C. Zhen, W. W. Yang, "Design and implementation of rural information management system based on SSI framework," Computer and Modernization, vol. 29, no. 7, pp. 156-159, 2013.

[4] L. J. Deng, Y. F. Zhang, J. M. Li, D. X. Dong, "Technology and application of SSI integration framework," Journal of Zhengzhou University of Light Industry(Natural Science Edition), vol. 30, no. 1, pp. 46-49, 2015.

[5] 360 personal library, "A variety of system architecture diagram and its brief introduction," http://www.360doc.com/content/12/1029/12/168576_244433043.shtml, 2017-1-10.

[6] X. N. Tian, Q. Zhao, "Design and implementation of attendance system based on SSI framework," Internet of Things Technologies, vol. 5, no. 2, pp. 76-77, 2015. 